\title{
Charge-density Distribution of Heptasulfur Imide $\left(\mathrm{S}_{7} \mathrm{NH}\right) \dagger$
}

\author{
Chih-Chieh Wang, Ying-Ying Hong, Chun-Her Ueng and Yu Wang* \\ Department of Chemistry, National Taiwan University, Taipei, Taiwan, Republic of China
}

\begin{abstract}
Heptasulfur imide, $\mathrm{S}, \mathrm{NH}$, was studied by $\mathrm{X}$-ray diffraction at both 100 and $300 \mathrm{~K}$ : space group $P n m a, Z=4$, $M_{\mathrm{r}}=239, a=7.842(2), b=13.115(2), c=7.6219(7) \AA$, at $100 \mathrm{~K} ; R=0.028$ and 0.029 for 2517 and 994 reflections at 100 and $300 \mathrm{~K}$ respectively. The crown shape of the compound is similar to that of cyclooctasulfur, with one sulfur atom replaced by an $\mathrm{NH}$ group. The experimental deformation density distribution reveals a large positive accumulation between the sulfur and nitrogen atoms; small accumulations were found between the sulfur atoms. A multipole refinement shows much clearer features in the bonding and lone-pair electron regions. The results of theoretical calculations by the extendedHückel molecular orbital, AM1 and $a b$ initio methods are compared with experimental results. There is evidence of bent $\mathrm{S}-\mathrm{N}$ bonds with endocyclic maxima in the deformation density distribution. The electrondensity distribution may be affected by the packing of molecules in the solid so that it differs from that of the isolated molecule. The net atomic charges from the multipole refinement indicate that $\mathrm{N}$ is negative, $\mathrm{H}$ is positive and $\mathrm{S}$ are neutral. However, those obtained from the ab initio method show a positive charge on the sulfur atom attached to the NH group.
\end{abstract}

The molecular structure of heptasulfur imide (cycloazaheptathiane, $\mathrm{S}_{7} \mathrm{NH}$ ) was studied by $\mathrm{X}$-ray diffraction at $-160^{\circ} \mathrm{C} .{ }^{1}$ In basic solution it undergoes disproportionation to yield $\mathrm{S}_{7} \mathrm{~N}^{-}, \mathrm{S}_{4} \mathrm{~N}^{-}$and $\mathrm{S}_{3}{ }^{-}$which were characterized by UV/VIS, ${ }^{2} \operatorname{Raman}^{3}$ and ${ }^{15} \mathrm{~N} \mathrm{NMR}^{4,5}$ spectroscopy.

Sulfur nitrogen compounds have been widely investigated ${ }^{6-10}$ in attempts to understand the nature of the S-S and $\mathrm{S}-\mathrm{N}$ bonds. It appears that a large variation in the $\mathrm{S}-\mathrm{N}$ bond lengths exists, the shortest being $1.416 \AA$ in $\mathrm{N}_{3} \mathrm{~S}_{3} \mathrm{~F}_{3}{ }^{9}$ and the longest being $1.77 \AA$ in sulfamic acid. ${ }^{10}$ This large range suggests the existence of different bonding modes. Sulfur-sulfur lengths also display a wide range, between $1.99 \AA$ in 4-phenyl1,2-dithiolylium cyanate $\left[\mathrm{PhC}_{3} \mathrm{H}_{2} \mathrm{~S}_{2}\right][\mathrm{SCN}]^{11}$ and $2.59 \AA$ in benzothiophenes. ${ }^{12.13}$ Correlations between the bond length and bond order of $\mathrm{S}-\mathrm{N}$ bonds have been proposed. ${ }^{14-16}$ Theoretical calculations on $\mathrm{S}_{4}(\mathrm{NH})_{4}{ }^{15}$ have even predicted bent bonds between $\mathrm{S}$ and $\mathrm{N}$ with density maxima outside the direct internuclear axis(exocyclic).

In order to facilitate further understanding of the $\mathrm{S}-\mathrm{N}$ and $\mathrm{S}-\mathrm{S}$ bonds of $\mathrm{S}_{7} \mathrm{NH}$, we have made structure analyses at both 100 and $300 \mathrm{~K}$. Experimental charge-density and multipole model density studies were performed on the $100 \mathrm{~K}$ data to elucidate the bonding properties. In addition, theoretical calculations on the isolated molecule based on extended Hückel molecular orbital (EHMO), Austin Model (AM1) and ab initio methods were also undertaken to study the bonding in terms of the electron-density distribution. From the comparison between experiment and theory we hoped to gain a better understanding of the nature of the $\mathrm{S}-\mathrm{S}$ and $\mathrm{S}-\mathrm{N}$ bonds.

\section{Experimental}

Heptasulfur imide was prepared from sodium azide $\mathrm{NaN}_{3}$ and sulfur in $\mathrm{P}\left(\mathrm{NMe}_{2}\right)_{3} \mathrm{O}$ under an atmosphere of $\mathrm{N}_{2}$, as previously described. ${ }^{17}$ It was then recrystallized from $\mathrm{MeOH}$. The infrared spectrum ( $\mathrm{KBr}$ pellet) showed bands at $3335 \mathrm{w}$ and $792 \mathrm{~m} \mathrm{~cm}^{-1}$. Suitable (light yellow) crystals were obtained by slow evaporation of a $\mathrm{MeOH}$ solution.

The crystal data and some details of the experimental

† Supplementary data available: see Instructions for Authors, J. Chem. Soc., Dalton Trans., 1992, Issue 1, pp. $x x-x x v$. conditions used in the present work are given in Table 1 . The intensity data were collected on a CAD4 diffractometer equipped with a graphite monochromator and $\mathrm{Mo-K} \alpha$ radiation $(\lambda 0.7107 \AA)$. They were measured up to $2 \theta=70$ and $92^{\circ}$ at 300 and $100 \mathrm{~K}$ respectively. In order to improve the data accuracy, more measurements were made at $100 \mathrm{~K}$. Two equivalent sets of reflections $(h k l, \bar{h} k l)$ were collected up to $2 \theta=92^{\circ}$. Seven measurements at $\psi$ values from -45 to $45^{\circ}$ with a step of $15^{\circ}$ were collected for each reflection up to $2 \theta=$ $44^{\circ}$. An additional set of reflections at $\psi=15^{\circ}$ was collected for $2 \theta$ between 44 and $80^{\circ}$. This yielded a total 13442 measurements, which gave 2978 unique reflections after averaging of equivalents $\left(R_{\mathrm{int}} 0.019\right)$. Three standard reflections monitored every hour throughout the measurement varied by less than $\pm 4 \%$. An analytical absorption correction was applied based on six measured faces of the crystal. Normal least-squares refinements based on $F_{\text {obs }}$ were performed; the weighting was calculated from counting statistics plus the $2 \%$ variation in intensity. The standard deviation of the averaged intensity was taken as the geometric mean of all the $\sigma$ values of equivalents. An extinction correction was tried in the least squares, but no effect was found. An additional high-order refinement was carried out based on data with $\left(\sin \theta / \lambda \geqslant 0.75 \AA^{-1}\right)$ in order to obtain all the non-hydrogen atomic parameters for the use in a promolecule model density calculation of the deformation density distribution. Maps of the experimental deformation density $\Delta \rho_{x-x}$ [equation (1)] were calculated from the

$$
\Delta \rho_{x-x}=\rho^{\text {obs }}-\sum_{i} \rho_{i}^{\text {atom }}=\frac{1}{V} \sum_{h}\left(k F_{h}^{\text {obs }}-F_{\mathrm{c}}\right) \exp 2 \pi i(\boldsymbol{h} \cdot \boldsymbol{r})
$$

Fourier transform of the corresponding difference in structure amplitudes $\left(k F_{\mathrm{o}}-F_{\mathrm{c}}\right)$, where $F_{\mathrm{c}}$ was calculated based on the high-order refinement, i.e. promolecule model. The hydrogen position was displaced along the $\mathrm{N}-\mathrm{H}$ vector to yield a $\mathrm{N}-\mathrm{H}$ bond length of $1.0 \AA^{18 a}$ Here $k$ is the optimum scale factor for the data range used in the Fourier synthesis $[(\sin \theta) / \lambda=$ $0-0.75 \AA^{-1}$ ] $V$ is the volume of the unit cell, and $h$ the Miller indices.

In addition, a model deformation density distribution $\Delta \rho_{m-a}$ based on a multipole model ${ }^{19}$ was calculated where $m$ represents the density of the multipole model $\rho^{\text {multipole }}$ and $a$ the neutral spherical atomic density (promolecule). Basically, this 
Table 1 Crystal data for $\mathrm{S}_{7} \mathrm{NH}^{a}$

\begin{tabular}{|c|c|c|}
\hline & $300 \mathrm{~K}$ & $100 \mathrm{~K}$ \\
\hline$a / \AA$ & $7.960(1)$ & $7.842(2)$ \\
\hline$b / \AA$ & $13.134(2)$ & $13.115(2)$ \\
\hline$c / \AA$ & $7.613(1)$ & $7.6219(7)$ \\
\hline$U / \AA^{3}$ & $795.9(3)$ & $783.9(4)$ \\
\hline Reflections used for cell parameter determination & 25 & 72 \\
\hline$\theta$ range $\left({ }^{\circ}\right)$ for cell parameter determination & $10-23$ & $14-38$ \\
\hline$D_{\mathrm{c}} / \mathrm{g} \mathrm{cm}^{-3}$ & 2.0 & 2.03 \\
\hline Crystal size $/ \mathrm{mm}$ & $0.5 \times 0.5 \times 0.3$ & $0.35 \times 0.26 \times 0.37$ \\
\hline$\mu / \mathrm{cm}^{-1}$ & 18.12 & 18.4 \\
\hline Transmission coefficients & & $0.628-0.712$ \\
\hline$\theta-2 \theta$ scan range $/^{\circ}$ & $1.6+0.7 \tan \theta$ & $2.2+0.7 \tan \theta$ \\
\hline $2 \theta_{\max } j^{\circ}$ & 70 & 92 \\
\hline No. of reflections measured & 3460 & 13442 \\
\hline No. of unique reflections & $1820[I \geqslant 3 \sigma(I), 994]$ & $2978[I \geqslant 3 \sigma(I), 2517]$ \\
\hline$R, R^{\prime b}$ & $0.029,0.020$ & $0.028,0.033$ \\
\hline$R, R^{\prime}\left(\sin \theta / \lambda>0.75 \AA^{-1}\right)$ & - & $0.027,0.026$ \\
\hline$h, k, l$ ranges & -12 to $12,-21$ to $21,-12$ to 12 & -15 to $15,-26$ to 26 \\
\hline
\end{tabular}

${ }^{a}$ Details in common: $M_{\mathrm{r}}=239.46$, orthorhombic, space group $P n m a, Z=4, F(000)=192 .{ }^{b} R$ and $R^{\prime}$ are defined as $R_{1}$ and $R_{1 \mathrm{w}}$ in Table 3 .

distribution is calculated in the same way as the experimental one, $\Delta \rho_{x-x}$, except that $\rho^{\text {obs }}$ was replaced by $\rho^{\text {multipole }}$ [equation (2)]. The first two terms are the spherical part of the

$$
\rho^{\text {multipole }}=\rho^{\text {core }}+P_{v} \rho^{\mathrm{val}}+\sum_{l=0}^{l} R_{l}(r) \sum_{m=-l}^{l} P_{l m} Y_{l m}
$$

electron density for the core and valence electrons respectively, the third is the sum of the multipole expansions in terms of the spherical harmonic series, $Y_{l m} ; R_{l}(r)$ is the Slater-type radial function, $P_{\mathrm{v}}$ and $P_{l \mathrm{~m}}$ are population coefficients which were obtained by least-squares refinement ${ }^{19}$ together with conventional positional and thermal parameters.

The deformation density distribution based on multipole refinement was calculated with a multipole expansion of the valence shell up to hexadecapoles for the $S$ atoms, octapoles for the $\mathrm{N}$ atom and dipoles for the $\mathrm{H}$ atom. The atomic scattering factors were calculated as the sum of the core and valence electron scattering factors with coefficients taken from ref. 18a. Neon and helium cores were used for $\mathrm{S}$ and $\mathrm{N}$ atoms respectively. The valence-electron configurations for $S$ and $N$ atoms were $s^{2} p^{4}$ and $s^{2} p^{3}$. A static multipole deformation density distribution was also calculated, in which all the thermal parameters $U_{i j}$ were set to zero and the Fourier summation calculated up to the limiting sphere of the Mo-K $\alpha$ radiation $\left(1.41 \AA^{-1}\right)$

All computations were carried out on a local MicroVaxIII computer using mainly NRCVAX ${ }^{20}$ programs. The multipole model was refined using the program MOLLY. ${ }^{19}$ The deformation density maps generated from both conventional and multipole refinement were produced by a locally developed contour-plotting program. ${ }^{21}$

Additional material available from the Cambridge Crystallographic Data Centre comprises thermal parameters and bond angles.

\section{Computational Procedure}

All the molecular orbital (MO) calculations were carried out using the coordinates obtained from the diffraction data at $100 \mathrm{~K}$. The theoretical deformation density was computed by subtraction of the sum of the spherical atomic density from the total electron density of the occupied molecular orbitals [equation (3), HOMO = highest occupied molecular orbital].

$$
\Delta \rho_{\text {theo }}=\sum_{i=1}^{\text {HOMO }} \rho_{i}^{\text {MO }}-\sum_{i} \rho_{i}^{\text {atom }}
$$

Extended Hückel calculations were made with the program ICON. ${ }^{22}$ The AM 1 calculation was made with the AMPAC program. $^{22}$ The AM1 parameters for sulfur were taken from ref. 23. The parameters for $\mathrm{N}$ and $\mathrm{H}$ were taken from the default values of the program. The $a b$ initio calculation was carried out using the program GAUSSIAN $90 .^{24}$ The molecular orbitals of an isolated $\mathrm{S}_{7} \mathrm{NH}$ molecule were obtained by making a singlepoint calculation at the restricted Hartree-Fock (RHF) level and using 3-21G and 3-21G* (split valence level with polarization function on $\mathrm{S}$ atom only) as basis sets. ${ }^{25}$ The spherical atomic density was computed using the same basis set at the restricted open-shell Hartree-Fock ROHF/GVB generalized valence bond level. All computations were carried out on a local MicroVaxIII computer. The deformation density maps were then produced by using the program MOPLOT ${ }^{22}$ and the contour plotted by the plotting program ${ }^{21}$ mentioned above.

\section{Results}

The atomic and thermal parameters from the full data and the high-order $\left[(\sin \theta) / \lambda>0.75 \AA^{-1}\right]$ refinements are given in Table 2. The thermal ellipsoids of the molecule at $100 \mathrm{~K}$ and the bond lengths at both 100 and $300 \mathrm{~K}$ are shown in Fig. 1(a). The thermal parameters of the non-hydrogen atoms are on average $30 \%$ of their room-temperature values at $100 \mathrm{~K}$. However, the anisotropy in the thermal vibration does not change significantly.

The experimental deformation density distributions in the planes of $\mathrm{S}(1)-\mathrm{N}-\mathrm{S}\left(1^{*}\right)$ and $\mathrm{S}(3)-\mathrm{S}(4)-\mathrm{S}\left(3^{*}\right)$ are shown in Fig. $2(a)$ and $2(b)$. There is a positive density accumulation along the $\mathrm{N}-\mathrm{S}$ bond in Fig. 2(a). There were actually three different deformation maps for the S-S-S planes, but only one is shown. Also one of the planes at the bisection of $S(1)-S(2)-S(3)$ angle is shown in Fig. 2(c). It is apparent that lone-pair electrons are located around the sulfur atom at the bisecting plane.

The local cartesian axes defined in the multipole model are indicated in Fig. 1(b). The results from the multipole refinements at various stages are compared in Table 3; the improvements in the agreement indices over the various stages of expanding the series are obvious. The final atomic parameters from this refinement are also given in Table 2. The net atomic charges of the atoms obtained from this refinement up to the monopole and hexadecapole terms are given in Table 4, with $\mathrm{N}$ bearing a negative charge, $\mathrm{H}$ a positive charge and $\mathrm{S}$ being neutral. The static multipole-model deformation density maps for all planes are shown in Fig. 3, their features being similar to those of the corresponding experimental maps. One experi- 
Table 2 Atomic fractional coordinates and thermal parameters obtained from $(a)$ full data refinement at $300 \mathrm{~K},(b)$ full data refinement at $100 \mathrm{~K},(c)$ high-angle $(\sin \theta / \lambda \geqslant 0.75)$ refinement at $100 \mathrm{~K}$ and $(d)$ multipole refinement

$\begin{array}{lllll}\text { Atom } & x & y & z & B_{\text {eq }} / \AA^{2} \\ \mathrm{~S}(1)(a) & 0.16940(1) & 0.36208(1) & 0.25639(1) & 4.170(5) \\ \mathrm{S}(1)(b) & 0.16326(4) & 0.36330(2) & 0.25445(3) & 1.30(1) \\ \mathrm{S}(1)(c) & 0.16327(4) & 0.36321(2) & 0.25428(4) & 1.21(1) \\ \mathrm{S}(1)(d) & 0.16326(2) & 0.36325(1) & 0.25427(2) & 1.264(5) \\ \mathrm{S}(2)(a) & 0.22965(1) & 0.41672(1) & 0.01377(1) & 4.676(5) \\ \mathrm{S}(2)(b) & 0.22402(3) & 0.41870(2) & 0.00978(3) & 1.44(1) \\ \mathrm{S}(2)(c) & 0.22388(4) & 0.41867(2) & 0.00988(4) & 1.35(1) \\ \mathrm{S}(2)(d) & 0.22396(2) & 0.41870(1) & 0.00993(2) & 1.400(5) \\ \mathrm{S}(3)(a) & 0.04297(1) & 0.37484(1) & -0.15793(1) & 4.713(6) \\ \mathrm{S}(3)(b) & 0.03297(4) & 0.37609(2) & -0.16295(3) & 1.46(1) \\ \mathrm{S}(3)(c) & 0.03288(4) & 0.37610(2) & -0.16295(5) & 1.38(1) \\ \mathrm{S}(3)(d) & 0.03299(2) & 0.37609(1) & -0.16298(2) & 1.422(5) \\ \mathrm{S}(4)(a) & 0.12664(2) & 0.2500 & -0.28913(2) & 4.838(9) \\ \mathrm{S}(4)(b) & 0.12034(5) & 0.2500 & -0.29543(5) & 1.45(1) \\ \mathrm{S}(4)(c) & 0.12026(6) & 0.2500 & -0.29567(6) & 1.36(1) \\ \mathrm{S}(4)(d) & 0.12031(4) & 0.2500 & -0.29560(3) & 1.408(1) \\ \mathrm{N}(a) & 0.26257(5) & 0.2500 & 0.28938(6) & 3.70(2) \\ \mathrm{N}(b) & 0.2610(2) & 0.2500 & 0.2877(2) & 1.26(5) \\ \mathrm{N}(c) & 0.2598(2) & 0.2500 & 0.2869(2) & 1.27(3) \\ \mathrm{N}(d) & 0.2601(2) & 0.2500 & 0.2867(2) & 1.33(3) \\ \mathrm{H}(a) & 0.3594(7) & 0.2500 & 0.2931(7) & 6.3 \\ \mathrm{H}(b) & 0.4008 & 0.2500 & 0.2856 & 2.0 \\ \mathrm{H}(c) & 0.4008 & 0.2500 & 0.2856 & 2.0 \\ \mathrm{H}(d) & 0.4008 & 0.2500 & 0.2856 & 2.0\end{array}$

$B_{\mathrm{eq}}=(8 / 3) \pi^{2} \Sigma_{i} \Sigma_{j} U_{i j} a_{i}^{*} a_{j}{ }^{*} a_{i} a_{j}$. (a)

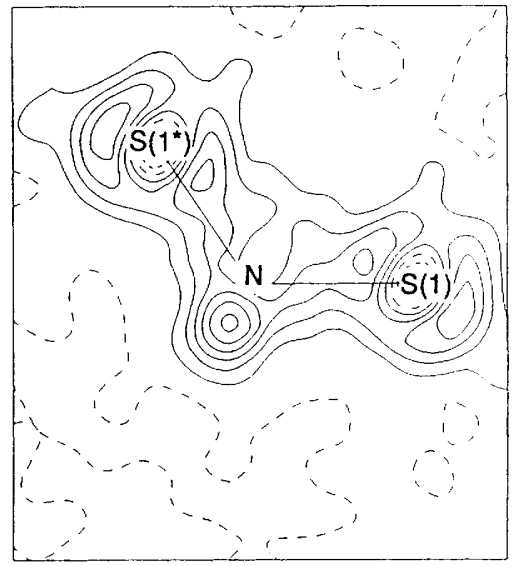

(b)

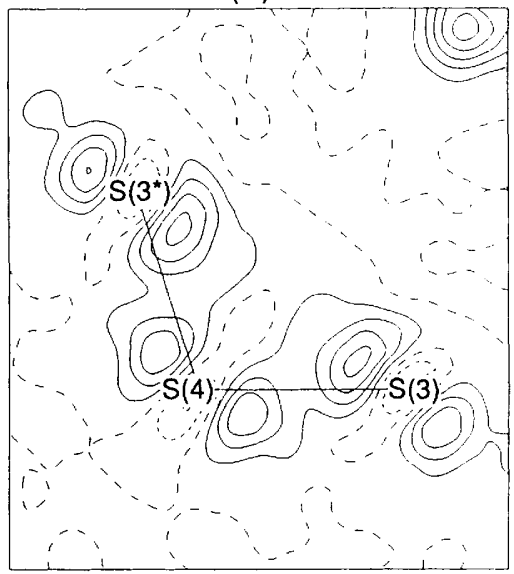

(c)

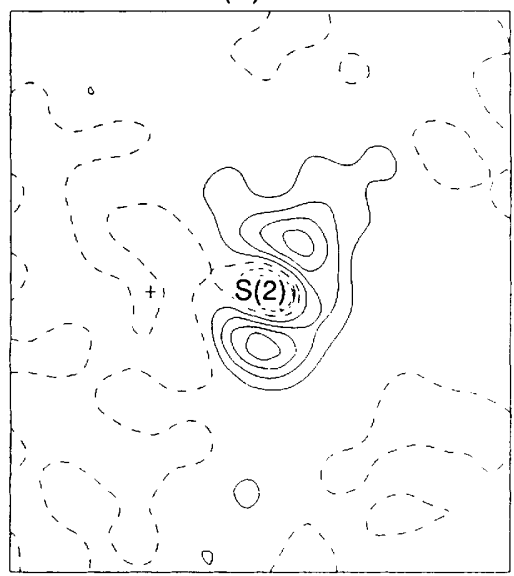

Fig. 2 Experimental deformation density maps, $\Delta p_{x-x}$, for $S_{7} \mathbf{N H}$. Contour lines (intervals of $0.1 \mathrm{e} \AA^{-3}$ ) represent positive (solid), zero (dashed) and negative (dotted) values. (a) $\mathrm{S}(1)-\mathrm{N}-\mathrm{S}\left(1^{*}\right)$ plane, $(b)$ $\mathrm{S}(3)-\mathrm{S}(4)-\mathrm{S}\left(3^{*}\right)$ plane, (c) plane perpendicular to $\mathrm{S}(1)-\mathrm{S}(2)-\mathrm{S}(3)$ and at the bisection of $S(1)-S(2)-S(3)$

mental deformation density concerning the intermolecular hydrogen bond is shown in Fig. 5. The theoretical deformation density maps of the isolated molecule computed by the $a b$ initio method for all the different S-S-S planes are essentially the same, so only one S-S-S plane is presented. The deformation density maps of the S-N-S, S-S-S planes and the plane at the bisection of S-S-S are shown in Fig. 4 as obtained by the $a b$ initio method.

The net atomic charges from three calculations are compared in Table 4 with results from the multipole refinement.
Fig. 1 (a) Molecular drawing of $\mathrm{S}_{7} \mathrm{NH}$ with thermal ellipsoids $(50 \%$ probability) at $100 \mathrm{~K}$. Bond lengths $(\AA)$ at 100 (top) and $300 \mathrm{~K}$ (bottom) are given. (b) Choice of local cartesian axes for the multipole refinements 
(a)

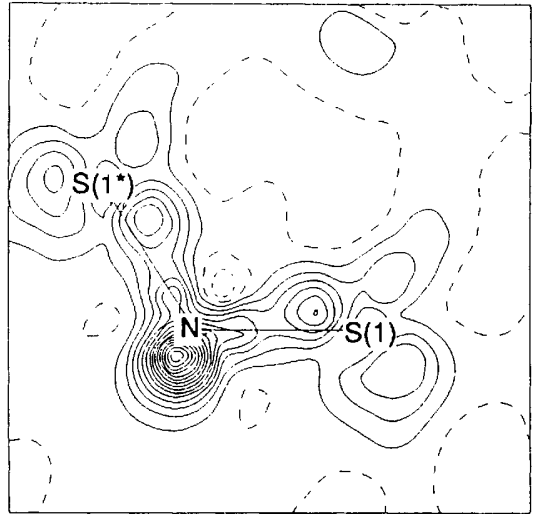

(b)

(b) (i)

(b) (ii)
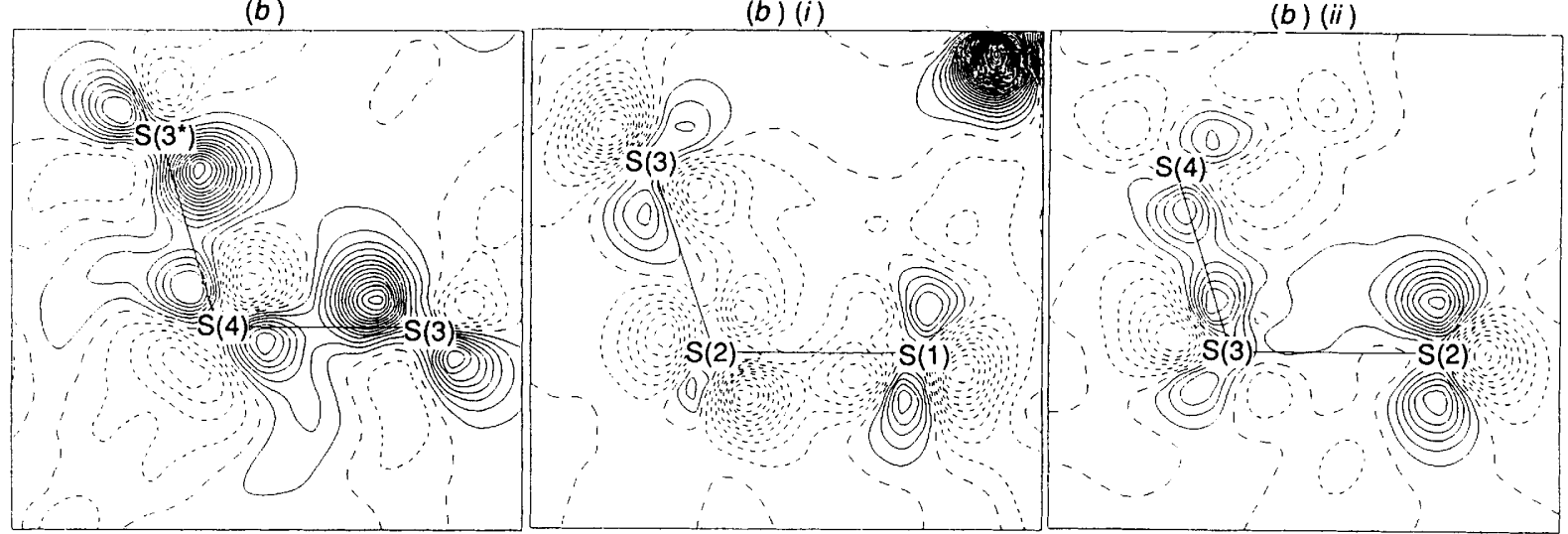

(c)

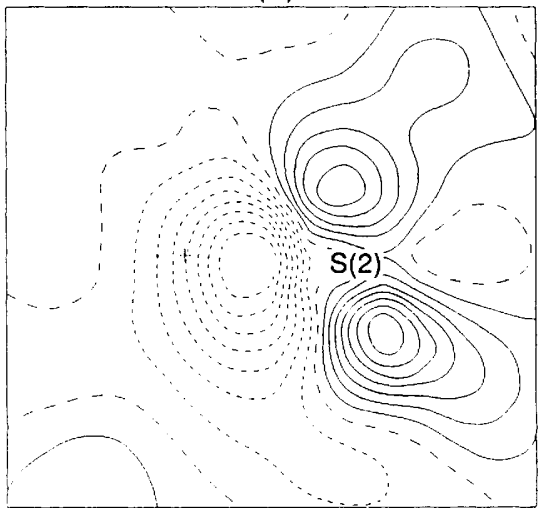

Fig. 3 Static multipole-model deformation density maps, $\Delta \rho_{m-a} ;(a)-(c)$ as in Fig. 2, there are two alternative S-S-S planes in $(b)$, where $(i)$ is $\mathrm{S}(1)-\mathrm{S}(2)-\mathrm{S}(3)$ and $(i i)$ is $\mathrm{S}(2)-\mathrm{S}(3)-\mathrm{S}(4)$

Table 3 Least-squares results of multipole refinements (based on $F$ )

$\begin{array}{lcllllll}\text { Method } & N_{\mathrm{v}} & k & R_{1} & R_{1 \mathrm{w}} & R_{2} & R_{2 \mathrm{w}} & S \\ \text { Conventional } & 42 & 0.890(1) & 0.0329 & 0.0327 & 0.0438 & 0.0514 & 3.015 \\ \text { Monopole } & 48 & 0.889(1) & 0.0319 & 0.0301 & 0.0420 & 0.0502 & 2.785 \\ \text { Octapole } & 113 & 0.8845(8) & 0.0246 & 0.0199 & 0.0247 & 0.0276 & 1.862 \\ \text { Hexadecapole }^{*} & 145 & 0.8841(8) & 0.0242 & 0.0194 & 0.0238 & 0.0268 & 1.822\end{array}$

$N_{\mathrm{v}}=$ number of variables, $N_{\mathrm{o}}=$ number of reflections; $R_{1}=\Sigma\left|F_{\mathrm{o}}-k F_{\mathrm{c}}\right| / \Sigma F_{\mathrm{o}}, R_{2}=\Sigma\left|F_{\mathrm{o}}{ }^{2}-k F_{\mathrm{c}}{ }^{2}\right| / \Sigma F_{\mathrm{o}}{ }^{2} ; R_{1 \mathrm{w}}=\left(\Sigma w\left|F_{\mathrm{o}}-k F_{\mathrm{c}}\right|^{2} / \Sigma w F_{\mathrm{o}}{ }^{2}\right)^{\frac{1}{2}}, R_{2 \mathrm{w}}=$ $\left(\sum w\left|F_{\mathrm{o}}{ }^{2}-k F_{\mathrm{c}}{ }^{2}\right|^{2} / \Sigma w F_{\mathrm{o}}{ }^{4}\right)^{\frac{1}{2}}$ and $S=\left[\Sigma w\left|F_{\mathrm{o}}{ }^{2}-k F_{\mathrm{c}}{ }^{2}\right|^{2} /\left(N_{\mathrm{o}}-N_{\mathrm{v}}\right)\right]^{\frac{1}{2}}$.

* Up to hexadecapole terms for the sulfur atoms only.

\section{Discussion}

The molecule of $\mathrm{S}_{7} \mathrm{NH}$ (Fig. 1) contains an eight-membered, puckered ring in a crown shape with the $\mathrm{H}$ atom bonded to the $\mathrm{N}$. The point group is $C_{s}$ with the molecular mirror plane passing through $\mathrm{H}, \mathrm{N}$ and $\mathrm{S}(4)$, coinciding with the crystallographic mirror plane at $z=\frac{1}{4}$. Bond lengths at $100 \mathrm{~K}$ are longer than those at room temperature due to libration effects. ${ }^{26-28}$ The S-N bond length is $1.6673(3) \AA$ at $300 \mathrm{~K}$, longer than some values in other $\mathrm{S}, \mathrm{N}$-heterocyclic compounds ${ }^{6,10}$ but certainly shorter than the value $(1.73 \AA)$ proposed for a single bond. ${ }^{14}$ Thus the $\mathrm{S}-\mathrm{N}$ bond order is probably greater than one, which is supported by both the 
Table 4 Atomic net charges

\begin{tabular}{lllllll} 
& \multicolumn{2}{c}{ Experimental } & \multicolumn{3}{c}{ Ab initio } \\
\cline { 2 - 4 } \cline { 5 - 7 } Atom & Monopole & Hexadecapole & EHMO & AM1 & $3-21 G$ & $3-21 G^{*}$ \\
$\mathbf{H}$ & $+0.49(2)$ & $+0.67(1)$ & +0.25 & +0.26 & +0.39 & +0.37 \\
$\mathbf{N}$ & $-0.86(4)$ & $-0.73(4)$ & -0.07 & -0.54 & -1.06 & -0.85 \\
$\mathbf{S}(1)$ & $+0.22(5)$ & $+0.06(4)$ & +0.01 & +0.28 & +0.43 & +0.32 \\
$\mathbf{S}(2)$ & $+0.15(5)$ & $+0.01(4)$ & -0.07 & -0.12 & -0.08 & -0.06 \\
$\mathbf{S}(3)$ & $-0.39(4)$ & $-0.08(3)$ & -0.02 & -0.02 & -0.01 & -0.01 \\
$\mathbf{S}(4)$ & $+0.41(3)$ & $+0.07(2)$ & -0.02 & +0.02 & -0.01 & -0.004
\end{tabular}

(a)

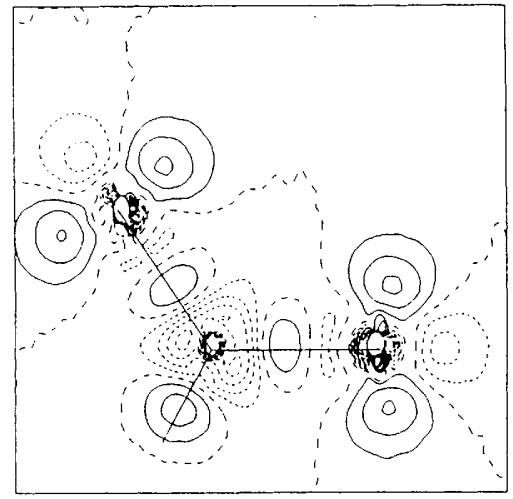

(b)

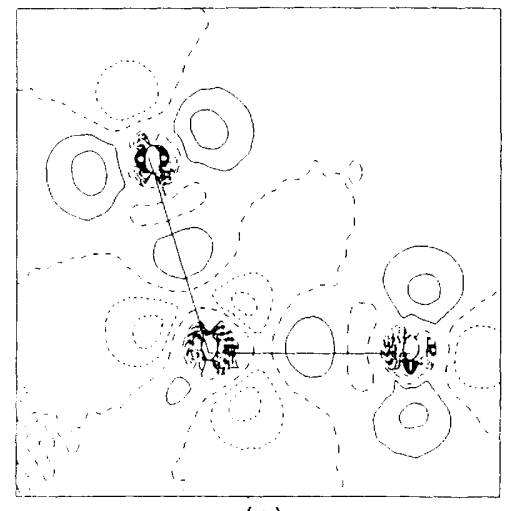

(c)

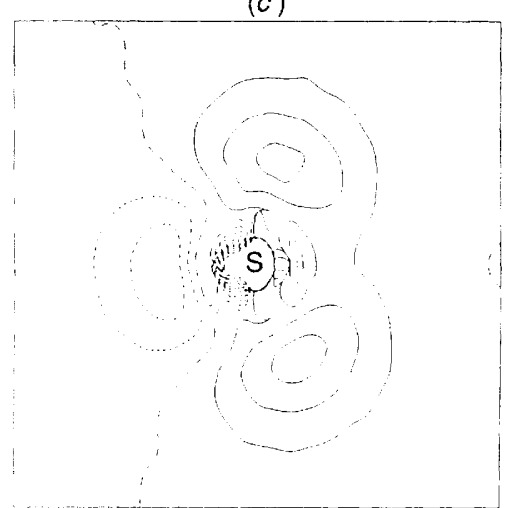

Fig. 4 Deformation density maps from ab initio calculations; details as in Fig. 2

experimental deformation density distribution and the theoretical calculation. The S-N-S $[122.97(1)]$ and $\mathrm{S}-\mathrm{N}-\mathrm{H}$ $\left[116.807(7)^{\circ}\right]$ angles are very similar to those of $\mathrm{S}_{4}(\mathrm{NH})_{4}{ }^{8}$ All the $\mathrm{S}-\mathrm{S}$ bond lengths of $\mathrm{S}_{8}{ }^{7}$ can be considered to be equivalent, averaging $2.045 \AA$. However, the replacement of one sulfur atom by an $\mathrm{NH}$ group appears to destroy this equivalency; the $\mathrm{S}-\mathrm{S}$ bond next to $\mathrm{S}-\mathrm{N}$ is shorter than the one next to it

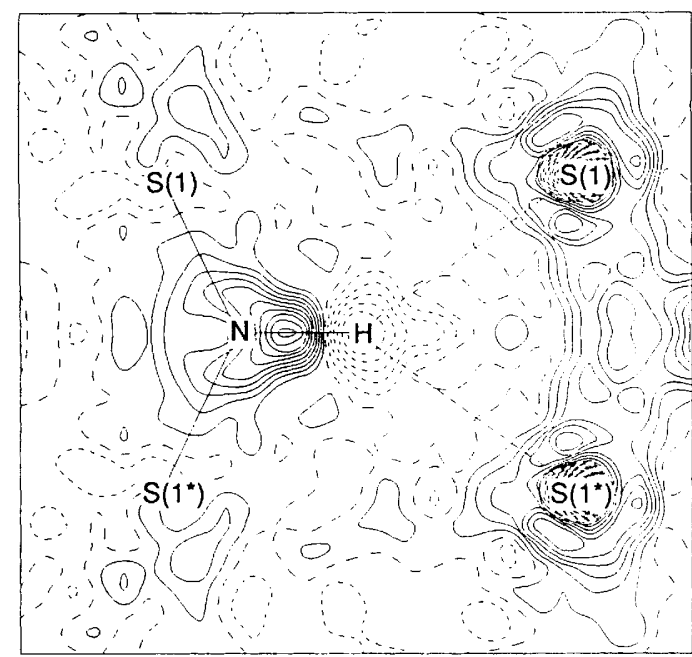

Fig. 5 Experimental deformation density, $\Delta \rho_{x-x}$, of the plane $\mathrm{S}(1) \cdots \mathrm{H} \cdots \mathrm{S}\left(1^{*}\right)$; dashed line indicates the intermolecular hydrogen bond

and an alternate short, long, short pattern is found, as in $\mathrm{S}_{7} \mathrm{NSN}\left(\mathrm{Me}_{2}\right){ }^{6}$

The net atomic charges from various calculation methods and the experimental values obtained from the multipole refinement are compared in Table 4 . In general, they indicate that the most negatively charged atom is $\mathrm{N}$ and the most positive is $\mathrm{H}$. This shows why heptasulfur imide has a strong acidic proton which reacts readily even with weak bases, ${ }^{2,3}$ for example it donates a proton to thiobis(amines), $\mathrm{S}\left(\mathrm{NR}_{2}\right)_{2}$, to yield $\mathrm{S}_{7} \mathrm{NSNR}_{2}$ and $\mathrm{NHR}_{2}\left(\mathrm{R}=\mathrm{Me}, \mathrm{Et}, \mathrm{Pr}^{\mathrm{i}}\right.$ or $\left.\mathrm{C}_{6} \mathrm{H}_{11}\right){ }^{6}$ The charges of all the $S$ atoms are roughly neutral, except in the case of $a b$ initio and AM1 calculations where the sulfur atoms next to $\mathrm{N}$ are strongly positive. There are severe limitations in comparing the net atomic charges obtained from Mulliken populations ${ }^{29}$ and those from charge-density experiments. This result may have some bearing on the alternation of $\mathrm{S}-\mathrm{S}$ bond length. Nevertheless, the latter effect is not revealed by the theoretical deformation density distribution.

The experimental deformation density $\left(\Delta \rho_{x-x}\right)$ distribution in the plane $\mathrm{S}(1)-\mathrm{N}-\mathrm{S}\left(1^{*}\right)$ shown in Fig. 2(a) clearly reveals the large density accumulation along the $\mathrm{N}-\mathrm{S}$ and $\mathrm{N}-\mathrm{H}$ bonds. Our results show that the $\mathrm{S}-\mathrm{N}$ bond maxima in the deformation density maps [Figs. $2(a)$ and $3(a)$ ] are endocyclic, similar to those found for $\mathrm{S}_{4}(\mathrm{NH})_{4}{ }^{8}$ experimentally, but differ from the theoretical calculations ${ }^{15}$ which predict exocyclic type bent bonds. The large deficiency in density near the sulfur nucleus in the experimental map, $\Delta \rho_{x-x}$ (Fig. 2), was observed in other sulfur-containing compounds, ${ }^{13,30-32}$ but not in the multipole deformation density $\Delta \rho_{m-a}$. Although the scale factor was optimized (refined) for the $(\sin \theta) / \lambda$ range adopted in the deformation density map, the large peaks around $\mathrm{N}$ and large holes around $\mathbf{S}$ still persist. This phenomenon may be a result of the large difference in atomic charges between $\mathrm{N}$ and $\mathrm{S}$. There is little density accumulation along the $\mathrm{S}-\mathrm{S}$ bonds but there is 
some positive density accumulation around the sulfur atoms. The static multipole-model deformation density maps [Fig. 3(a) and $3(b)$ ] show similar features to the experimental ones; however, these features are more pronounced than in the experimental maps. The experimental and the multipole deformation density distributions of three crystallographically different S-S-S planes apparently show significant differences; such differences were also found in $\mathrm{S}_{4}(\mathrm{NH})_{4},{ }^{8}$ and were ascribed to the effect of intermolecular hydrogen bonds. The reason for the differences among the $\mathrm{S}-\mathrm{S}$ bonds in the present compound is not clear, since there are no strong intermolecular interactions in this crystal; the non-bonding $\mathrm{S} \cdots \mathrm{S}$ or $\mathrm{S} \cdots \mathrm{N}$ contacts are greater than 2.97 and $3.07 \AA$ respectively, and only one intermolecular hydrogen bond is possible (Fig. 5 where the similar effect of density polarization toward the hydrogen bond ${ }^{8}$ is seen), but this only provides an explanation for one sulfur atom $[\mathrm{S}(1)]$ being different from the others. However, it is interesting that the packing of $\mathrm{S}_{7} \mathrm{NH}$ is very much the same as that in $\mathrm{S}_{4}(\mathrm{NH})_{4} \cdot{ }^{+}{ }^{8}$ These differences are not observed in any theoretical deformation density map. This means that all the $\mathrm{S}-\mathrm{S}$ bonds in the isolated molecule are chemically equivalent, but not equivalent in the solid, although the intermolecular interactions are not apparently strong. The distribution maxima of the lone-pair electrons around the $S$ atom are located about $0.75 \AA$ above and below the S-S-S plane [Figs. $2(c), 3(c)$ and $4(c)]$ both in the experimental and theoretical deformation density maps, suggesting an orbital of mostly $p$ character.

In theoretical calculations, the addition of d-polarization functions for the sulfur atoms lowers the energy and enhances the S-S bond density [Fig. 4(a) $-4(c)$ ], as observed in other sulfur-containing compounds. ${ }^{15} \mathrm{~A}$ comparison between the static and theoretical deformation density maps shows only limited agreement. In static maps more electron density along the bonds, and less in the region of the lone pairs, is apparent, compared with the theoretical maps. The electrondensity distribution in the theoretical maps from $a b$ initio calculation is better represented along the bonds than in those from the semiempirical AM1 and EHMO calculations.

\section{Conclusion}

Evidence for bent $\mathrm{S}-\mathrm{N}$ bonds with endocyclic maxima is confirmed by the experimental deformation density distribution. The inherent symmetry of the isolated molecule may not exist in the solid state; the packing of molecules in the crystal may polarize the electron-density distribution. The inclusion of d-polarization functions for the sulfur atoms in the molecular orbital calculation is important for bonding density studies.

\section{Acknowledgements}

We thank Mr. Claus of the Max Planck Institute für
Kohlenforschung for help on the data collection at $100 \mathrm{~K}$. This work was supported by the National Science Council of the Republic of China.

\section{References}

1 H. J. Hecht, R. Reinhardt, R. Steudel and H. Z. Bradaczek, Z. Anorg. Allg. Chem. 1976, 426, 43.

2 P. Dubois, J. P. Lelieur and G. Lepoutre, Inorg. Chem., 1988, 27, 3032.

3 T. Chivers and C. Lau, Inorg. Chem., 1982, 21, 453.

4 I. P. Parkin, J. D. Woollins and P. S. Belton, J. Chem. Soc., Dalton Trans., 1990, 511.

5 T. Chivers, D. D. Mclntyre, K. J. Schmidt and H. J. Vogel, J. Chem. Soc., Chem. Commun., 1990, 1341.

6 R. B. Bruce, R. J. Gillespie and D. S. Slim, Can. J. Chem., 1978, 56, 2927.

7 P. Coppens, Y. W. Yang, R. H. Blessing, W. F. Cooper and F. K. Larsen, J. Am. Chem. Soc., 1977, 99, 760.

8 D. Gregson, G. Klebe and H. Fuess, J. Am. Chem. Soc., 1988, 110 8488.

9 O. Glemser, Angew. Chem., Int. Ed. Engl., 1963, 2, 530.

10 B. Sharma and J. Donohue, Acta Crystallogr., 1963, 16, 891

11 A. Hordvik, Q. Rep. Sulfur. Chem., 1970, 5, 21.

12 A. Hordvik and L. J. Saethre, Is. J. Chem., 1972, 10, 239.

13 Y. Wang, M. J. Chen and C. H. Wu, Acta Crystallogr., Sect. B, 1988, 44, 179 .

14 A. Karpfen, P. Schuster, J. Petkov and H. Lisdika, J. Chem. Phys., $1978,68,3884$.

15 A. E. Foti and V. H. Smith, Mol. Phys., 1978, 1, 111

16 L. Behera, T. Kar and A. B. Sannigrahi, J. Mol. Struct. (Theochem.), 1990, 209, 111.

17 B. E. Douglas, Inorg. Synth., 1978, 13, 204.

18 International Tables for X-Ray Crystallography, Kynoch Press, Birmingham, 1974; (a) vol. 3; (b) vol. 4.

19 N. Hansen and P. Coppens, Acta Crystallogr., Sect. A, 1978, 34, 909.

20 E. J. Gabe, F. Lee and Y. LePage, Crystallographic Computing 3, eds. G. M. Sheldrick, C. Kruger and R. Goddard, Clarendon Press, Oxford, 1985, pp. 167-174.

21 C. J. Tsai, Masters Thesis, National Taiwan University, 1983.

22 ICON, MOPLOT and AMPAC programs, Quantum Chemistry Program Exchange, Indiana University, Bloomington, IN

23 M. J. S. Dewar and Y. C. Yuan, Inorg. Chem., 1990, 29, 3881

24 M. J. Frisch, M. Head-Gordon, G. W. Trucks, J. B. Foresman, H. B. Schlegel, K. Raghavachari, M. A. Robb, J. S. Binkley, C. Gonzalez, D. J. Defrees, D. J. Fox, R. A. Whiteside, R. Seeger, C. F. Melius, J. Baker, R. L. Martin, L. R. Kahn, J. J. P. Stewart, S. Topiol and J. A. Pople, GAUSSIAN 90, Gaussian Inc., Pittsburgh, PA, 1990.

25 K. J. Lin, C. C. Wang and Yu Wang, J. Chin. Chem. Soc., 1991, 38, 505.

26 Y. Wang, R. H. Blessing, F. Ross and P. Coppens, Acta Crystallogr., Sect. B, 1976, 32, 572.

27 J. W. Bats, P. Coppens and T. F. Koetzle, Acta Crystallogr., Sect. B, $1977,33,37$.

28 W. R. Busing and H. A. Levy, Acta Crystallogr., 1964, 17, 142

29 A. E. Reed, R. B. Weinstock and F. Weinhold, J. Chem. Phys., 1985, 83, 735 .

30 Y. Wang, L. W. Gwo, H. C. Lin, C. T. Kao, C. J. Tsai and J. W. Bats, Inorg. Chem., 1988, 27, 520 .

31 Y. Wang and J. H. Laio, Acta Crystallogr., Sect. B, 1989, 45, 65.

32 Y. Wang, N. L. Chang and C. T. Pai, Inorg. Chem., 1990, 29, 3256. 